\title{
Fortune of Reversals: How Randomized Clinical Trials Shape Medical Practice
}

\author{
Amnon Sonnenberg $^{1,2} \cdot$ Gennadiy Bakis $^{1}$
}

Accepted: 18 August 2021 / Published online: 31 August 2021

This is a U.S. government work and not under copyright protection in the U.S.; foreign copyright protection may apply 2021

\section{Introduction}

The lengthy process of becoming a physician, requiring well over a decade of pre-medical, medical, and postgraduate education and training culminates in the production of a young physician, brimming with knowledge and knowhow. What many of these physicians might not realize is that much of their knowledge and practice is not based on rigorous scientific data but rather on handed-down traditions from previous eras that may, when seriously scrutinized, be overly expensive, time-consuming, ineffective, or even dangerous. In this editorial, the authors will discuss why and how these practices came about and why some have been invalidated, focusing on an article published in this issue of Digestive Diseases and Science [1].

\section{A Culture of Fear}

Besides ignorance, ineffective medical practice is often driven by widespread and prevailing fears among physicians of missing a diagnosis and being sued for having failed to appropriately manage serious disease conditions or prevent digestive cancers in a timely manner [2]. In their quest to alleviate such fears, gastroenterologists - as much as any other practitioners - resort to many seemingly precautionary measures, which are unnecessary, costly, and potentially dangerous to the patient. Screening and surveillance colonoscopies are scheduled more frequently than recommended by accepted guidelines [3-8]. Instead to resorting

Amnon Sonnenberg

sonnenbe@ohsu.edu

1 Division of Gastroenterology and Hepatology, Oregon Health \& Science University, Portland, OR, USA

2 Gastroenterology Section, Portland VA Medical Center, P3-GI, 3710 SW US Veterans Hospital Road, Portland, OR 97239, USA to expectant management, we pursue diagnoses with low pre-test probabilities, applying costly and invasive test procedures with low yield. Even after negative test results, the search for the elusive source of a GI hemorrhage is continued with repetitive and fruitless use of unhelpful upper and lower GI endoscopies [9]. Patients with inflammatory bowel disease evaluated in the ER with abdominal pain are subjected to repetitive abdominal CT scans in short order [10]. Due to exaggerated fears about adverse events associated with long-term anti-secretory medications, even patients with severe erosive esophagitis or peptic strictures are deprived of effective treatment with proton pump inhibitors (PPI) or have such treatment discontinued prematurely [11]. Patients with imagined or functional bowel disorders are followed for prolonged time periods and subjected to countless tests and unnecessary surgeries [12, 13]. Medical charts become bloated with copied and pasted notes, trying to cover all bases and demonstrate one's diligence, caution, and care [14]. Other examples abound.

\section{Influence of Rules and Rituals}

The availability of any medical tool provides its practitioners with the comfort of being able to affect the course of the disease and remain in control, even if such actions amount to little more but a useless ritual $[15,16]$. Parts of the physical exams have been advocated as means of giving patients comfort and reassurance [17]. Many rituals are introduced into medical practice based on theoretical considerations alone without ever being subjected to rigorous testing [18]. All records of outpatient visits are still expected to include a full review of systems, social, occupational, and family history, as well as a complete physical exam, even in instances of a clear-cut digestive focus, such as hematemesis, melena, hematochezia, dysphagia, diarrhea and alike. Frequently, such measures are being justified as means of quality assurance and patient safety. For instance, the practice of 
pre-procedural "time-out" has been adopted by endoscopy centers following the model of surgical practice without ever testing its appropriateness or benefits to endoscopic procedures. At many institutions, each endoscopy is accompanied by a set of 2-4 pre-procedural and yet another set of 2-4 post-procedural chart notes, all in the name of safety and precaution, but more likely protecting the institution rather than benefiting the patients.

\section{Cost and Benefit Shifting}

Ideally, medicine is practiced by physicians unencumbered by outside pressure or personal interests. The patients' concerns to see their symptoms relieved and future disease prevented should be the only driving motivation for all medical pursuits. In reality, however, physicians are exposed to outside influence and pressure on how to conduct their practice. Gastroenterologists have to adjust their prescriptions and interventions according to restrictions imposed by health insurers and demands by healthcare administrators in order to generate more revenue and see more patients in increasingly shorter time periods [19-21]. The practice of endoscopy, the conduct of patient encounters, and the documentation of all healthcare activity is increasingly shaped by the rules of healthcare administrators with little or no knowledge about the exigencies of clinical gastroenterology. The occurrence of mental "burnout" is a reflection on physicians trying to reconcile the requisites of good medical care with prohibitive administrative demands [22, 23], mostly based on economic models and legal concerns, but rarely if ever on rigorous prospective scientific analysis.

Besides outside pressure, the practice of gastroenterology is also shaped by physicians' very own set of interests. In general, physicians like to utilize the set of tools, with which they are familiar and have used many times before. Surgeons like to operate, and gastroenterologists like to endoscope. In case of doubt, they will first seek a solution utilizing the armamentarium most accessible to them. This perspective becomes even more biased by the simple fact that physicians are relatively well remunerated for their procedural efforts. Each endoscopy financially benefits the endoscopists and their institution. A tell-tale example is provided by the patients with functional bowel disorders, who all too frequently undergo unnecessary endoscopic or surgical procedures $[12,13]$. In trying to balance the cost-benefit relationship of planned interventions, it is challenging for the physician to clearly differentiate between benefit to oneself and to the patient [24]. Similarly, one is less inhibited in utilizing ineffective medical means if the costs of such behavior are borne by others (patient or society). To alleviate personal concerns about potential future lawsuits, the physician is more inclined to order additional tests that are costly but of little benefit to the patient. In essence, cost to the patient may be beneficial to the physician and, vice-versa, benefit to the patient may be costly to the physician. Overall, the unhealthy mixture of outside pressure and personal interests may result in illogical behavior associated with overuse, as well underuse, of medical interventions.

\section{Bias Against Reversals}

"Reversals" are defined as the procedure of discarding familiar and established medical practices on the basis of rigorous scientific evidence that reveal these practices to be inefficient, overly costly, ineffective, or even downright dangerous. There are innumerous factors that eventually affect the adoption or reversal of medical practices. The authors of a systematic review published in the current issue of Digestive Diseases and Sciences address examples of reversals of prior medical practices manage to highlight the breadth and the complexity of this topic as it pertains to gastroenterology [1]. The article should serve a reminder about the high prevalence of outdated or invalid practice patterns that fail to show efficacy when exposed to rigorous testing.

Multiple factors affect the uptake of ineffective, costly, and potentially dangerous medical practices in gastroenterology. As gastroenterologists, we must honestly ask ourselves, why is there any need for such reversals at all? What are the reasons that our medical practice has become clogged with ineffective or redundant practice patterns? The results obtained from randomized clinical trials (RCT) provide an excellent instrument to fend off outside demands and help advocate for the rule of reason and science in medicine. Reversals of established misconceptions are part and parcel of a healthy scientific process. Leaving ineffective or harmful medical interventions by the wayside is beneficial to the patients and cost-saving for society as a whole. The publication by Yopes and coworkers of reversals in gastroenterology should be more than welcome [1]. It often takes additional courage to embark on such scientific pursuits and advance controversial ideas through a biased review process. There is a general bias in favor of publishing positive results and against publishing negative outcomes [25]. Publications in gastroenterology (as well as in any other branch of medicine or science) are also driven by an underlying bias (by authors, reviewers, and editors alike) to demonstrate that the tools of the trade are efficacious and cost-effective.

\section{Benefits of Randomized Clinical Trials}

RCT and their outcomes should be the final arbiter for the judgment in favor or against any type of medical diagnostic or treatment. RCT are especially suited to prospectively 
evaluate the efficacy of individual tests, medications, and interventional procedures. Increasing regulations and administrative oversight of their conduct have substantially increased the time and workload associated with randomized clinical trials, frequently rendering them prohibitively expensive. To reach unequivocal answers of sufficient statistical power, investigators need to recruit hundreds of patients from multiple medical centers. The organization and management of such multicentered trials requires its own staff of auxiliary personnel and administrators. Unless there is a pharmaceutical company or governmental agency with vested interest in the outcome, it is extremely difficult to finance and execute such large enterprises. There is a striking imbalance between the ease with which administrative rules and rituals become implemented, and the time and effort it takes to subject such measures to rigorous testing. Unfortunately, only limited resources are available to rigorously evaluate and eliminate all ineffective practice patterns, in particular those that encroach and stifle healthcare delivery, rendering it more expensive and inaccessible to patients. Randomized clinical trials are also limited in assessing the outcomes of decisions that are driven by political, social, and cultural influences and that shape the way we practice our subspecialty. In such instances, epidemiologic studies, outcomes research, and database analyses sometimes help filling the gap left by randomized clinical trials.

\section{Conclusions}

In the long run, science and technology are the only efficacious and lasting means to change physician behavior and the face of gastroenterology. RCT and epidemiologic studies are an invaluable part of our available instruments to achieve such goals. Practitioners should be constantly aware that much of their medical practice is shaped by tradition rather than by science, and thus subject to reversal as knowledge increases.

Author's contribution Conception and design: AS; writing of manuscript: AS, GB.

\section{Declarations}

Conflict of interest No financial support was received for this study. A Sonnenberg and G Bakis have no conflict of interest to declare.

\section{References}

1. Yopes M, Mozeika A. Liebling S, Haslam A, Prasad V, Lebwohl B. An analysis of five years of randomized trials in gastroenterology and hepatology reveals 52 medical reversals. Dig
Dis Sci. (Epub ahead of print). doi: https://doi.org/10.1007/ s10620-021-07199-5.

2. Sonnenberg A, Boardman CR. Cost of fear. Am J Gastroenterol 2013;108:173-5.

3. Burnand B, Harris JK, Wietlisbach V, et al. Use, appropriateness, and diagnostic yield of screening colonoscopy: an international observational study (EPAGE). Gastrointest Endosc 2006;63:1018-1026.

4. Argüello L, Pertejo V, Ponce M, et al. The appropriateness of colonoscopies at a teaching hospital: magnitude, associated factors, and comparison of EPAGE and EPAGE-II criteria. Gastrointest Endosc 2012;75:138-145.

5. Hassan C, Bersani G, Buri L, et al. Appropriateness of upper-GI endoscopy: an Italian survey on behalf of the Italian Society of Digestive Endoscopy. Gastrointest Endosc 2007;65:767-774.

6. Keren D, Rainis T, Stermer E, et al. A nine-year audit of open-access upper gastrointestinal endoscopic procedures: results and experience of a single centre. Can J Gastroenterol 2011;25:83-88.

7. Rubenstein JH, Pohl H, Adams MA, et al. Overuse of repeat upper endoscopy in the Veterans Health Administration: a retrospective analysis. Am J Gastroenterol 2017;112:1678-1685.

8. Gluskin AB, Dueker JM, Khalid A. High rate of inappropriate fecal immunochemical testing at a large Veterans Affairs health care system. Fed Prac 2021;38:270-5.

9. Woodward Z, Williams JL, Sonnenberg A. Length of endoscopic workup in gastrointestinal bleeding. Eur J Gastroenterol Hepatol 2016;28:1166-71.

10. Dotson JL, Kappelman MD. Overuse of the emergency department and CT scans in pediatric IBD - Time for hot spotting? JPGN 2015;61:267-70.

11. Maret-Ouda J, Markar SR, Lagergren J. Gastroesophageal reflux disease: a review. J Am Med Ass 2020;324:2536-2547.

12. Longstreth GF, Wilson A, Knight K, et al. Irritable bowel syndrome, health care use, and costs: a U.S. managed care perspective. Am J Gastroenterol 2003;98:600-607.

13. Cole JA, Yeaw JM, Cutone JA, et al. The incidence of abdominal and pelvic surgery among patients with irritable bowel syndrome. Dig Dis Sci 2005;50:2268-2275

14. Vogel L. Cut-and-paste clinical notes confuse care, say US internists. Can Med Ass J 2013;185:E826.

15. Sonnenberg A. Cost and benefit of medical rituals in gastroenterology. Aliment Pharm Ther 2004;20:939-42.

16. Sonnenberg A. Rituals in gastrointestinal endoscopy at the crossroad of shaman and science. Endosc Int Open 2017;5:E627-9.

17. Hosamani P. Verghese A. Annals for hospitalists inpatient notes - rituals in chaos, the sacred in the profane. Ann Intern Med 2017; 166:HO2.

18. Prasad VK, Cifu AS. Ending medical reversal - improving outcomes, saving lives. Johns Hopkins University Press, Baltimore, MD, 2015.

19. Yadav A, Foromera J, Feuerstein I, Falchuk KR, Feuerstein JD. Variations in health insurance policies regarding biologic therapy use in inflammatory bowel disease. Inflamm Bowel Dis 2017;23:853-7.

20. Naga HI, Mellia JA, Diatta F, et al. Beyond the hernia repair: a review of the insurance coverage of critical adjuncts in abdominal wall reconstruction. Plast Reconstr Surg Glob Open 2020;8:e3309.

21. Anonymus. 'Gold cards' allow Texas docs to skip prior authorizations. GI \& Hpeatology News, July 23, 2021. Accessed at: https:// www.mdedge.com/gihepnews/article/243271/diabetes/gold-cardsallow-texas-docs-skip-prior-authorizations. Last accessed on $7 / 28 / 2021$.

22. Ong J, Swift C, Ong S, Lim WY, Al-Naeeb Y, Shankar A. Burnout in gastroenterology registrars: a feasibility study conducted 
in the East of England using a 31-item questionnaire. BMJ Open Gastroenterol 2020;7:e00401.

23. Ramrakhiani NS, Morikawa C, Shetler K. Gastroenterology providers spend an additional 45-50 minutes on electronic health records per hour of scheduled time. Clin Gastroenterol Hepatol 2021;19:1489-90.

24. Sonnenberg A, Bakis G. Failure of cost-benefit analysis in gastrointestinal endoscopy. Endoscopy International Open 2019;7:E1537-9.
25. Spiegel B, Lacy BE. Negative is positive. Am J Gastroenterol 2016;111:1505.

Publisher's Note Springer Nature remains neutral with regard to jurisdictional claims in published maps and institutional affiliations. 